\title{
Rare pathological variants and presentations of primary central nervous system lymphomas
}

\author{
Arnaldo Neves Da Silva, M.D., Maria Beatriz Lopes, M.D., And David Schiff, M.D. \\ Departments of Neurology, Division of Neuro-Oncology; and Pathology, Division of Neuropathology, \\ University of Virginia Health System, Charlottesville, Virginia
}

\begin{abstract}
$\checkmark$ Primary central nervous system lymphoma (PCNSL) is a rare form of primary brain neoplasm, accounting for less than $3 \%$ of all primary brain tumors. Ninety percent of cases involve a large B-cell lymphoma that presents as a homogeneously enhancing lesion or lesions, typically deep-seated in the brain parenchyma. The authors describe unusual pathological forms of PCNSLs, including low-grade, T-cell, and Burkitt types, and also rare presentations such as neurolymphomatosis and pituitary lymphomas.
\end{abstract}

\section{KEY WORDS • primary central nervous system lymphoma • T-cell primary central nervous system lymphoma - Burkitt lymphoma • leptomeningeal tumor • neurolymphomatosis}

$\mathrm{P}$ rimary CNS lymphoma is a rare form of extranodal non-Hodgkin lymphoma that arises within and remains confined to the CNS. The PCNSLs must be differentiated from secondary involvement of the CNS in systemic lymphomas. The incidence of PCNSL increased almost threefold between 1973 and 1984, ${ }^{11}$ and continues to rise in all age groups and in both sexes, ${ }^{35}$ although recent reports support the suggestion that the annual incidence has been stabilizing or slightly declining. ${ }^{23}$ Data from the Central Brain Tumor Registry of the United States show that PCNSLs accounted for $2.7 \%$ of all primary brain tumors between 1995 and $1999 .{ }^{7}$ Only 1 to $2 \%$ of patients with non-Hodgkin lymphoma present with primary CNS disease at initial diagnosis. ${ }^{14}$

Diffuse large B-cell lymphoma accounts for approximately $90 \%$ of all PCNSLs, affecting the brain parenchyma with or without concomitant ocular or leptomeningeal involvement. ${ }^{4}$ The remaining $10 \%$ of cases comprise even more rare pathological entities such as low-grade PCNSLs, T-cell lymphomas, and Burkitt lymphomas. ${ }^{41}$

The purpose of this report was to focus on these uncommon pathological variants of PCNSL and also the unusual forms in which the lesions may present, such as neurolymphomatosis and pituitary lymphomas. Because of significant overlap with other papers on this topic, rare forms of presentation of PCNSL such as primary leptomeningeal lymphoma and primary dural lymphoma will be omitted.

\footnotetext{
Abbreviations used in this paper: $\mathrm{CI}=$ confidence interval; $\mathrm{CNS}$ $=$ central nervous system; $\mathrm{CSF}=$ cerebrospinal fluid; $\mathrm{CT}=$ computed tomography; IELSG = International Extranodal Lymphoma Study Group; IPCG = International PCNSL Collaborative Group; $\mathrm{MR}=$ magnetic resonance; PCNSL = primary CNS lymphoma.
}

\section{Low-Grade PCNSL}

Low-grade PCNSL represents a less aggressive PCNSL subgroup that is analogous to systemic low-grade nonHodgkin lymphoma. ${ }^{22}$ Very few cases have been reported in the literature, most of them including patients in whom tests for the human immunodeficiency virus are positive. Recently, results from an international study on low-grade PCNSL were published. ${ }^{21}$ In this report, the IPCG compiled data on 40 immunocompetent patients from 18 cancer centers in five countries (Table 1). The diagnosis of low-grade PCNSL was based on morphological tumor cell appearance and, if performed, on immunophenotyping, including the proliferation index and detection of rearranged immunoglobulin heavy-chain genes by polymerase chain reaction. The proliferation index (Ki 67, MIB-1 antibody) had to be $20 \%$ or less, in contrast with high-grade PCNSL, in which the proliferation index is usually higher than $50 \% .{ }^{27}$ Thirty-two patients $(80 \%)$ had a B-cell lymphoma and eight (20\%) had a T-cell lymphoma.

In 37 patients $(92.5 \%)$ there was involvement of a cerebral hemisphere or deeper brain structures, four patients showed leptomeningeal involvement (exclusive in two), and one had isolated spinal cord disease. The MR imaging features usually not seen in high-grade PCNSL included the following: hyperintensity on $\mathrm{T}_{2}$-weighted images in 16 patients, inhomogeneous contrast enhancement in 11, moderate contrast enhancement in 11, absent contrast enhancement in one, and lack of periventricular localization in 10 (Fig. 1).

Clinically, seizures were the most frequent symptom of presentation and mental changes were rather uncommon. In contrast, among patients with high-grade PCNSL the major initial symptom is mental status changes, whereas epilepsy is less frequent., ${ }^{4,18}$ 
A. Neves Da Silva, M. B. Lopes, and D. Schiff

TABLE 1

Characteristics of 40 patients with low-grade PCNSL compared with 378 with PCNSL from the IELSG cohort*

\begin{tabular}{|c|c|c|}
\hline Characteristic & No. w/ Low-Grade PCNSL (\%) & $\%$ of Patients in IELSG \\
\hline \multicolumn{3}{|l|}{ age $\dagger$} \\
\hline$\geq 60 \mathrm{yrs}$ & $21(53)$ & - \\
\hline$\geq 70 \mathrm{yrs}$ & $3(8)$ & 14 \\
\hline no. of men & $18(45)$ & 58 \\
\hline B symptoms & $0(0)$ & 2 \\
\hline \multicolumn{3}{|l|}{ symptoms at presentation $末$} \\
\hline seizures & 15 of $34(44)$ & - \\
\hline focal motor \& sensory deficits & 12 of $34(35)$ & - \\
\hline mental changes & 8 of $34(24)$ & - \\
\hline headache & 6 of $34(18)$ & - \\
\hline cerebellar symptoms & 6 of $34(18)$ & - \\
\hline hemiparesis & 3 of $34(9)$ & - \\
\hline \multicolumn{3}{|l|}{ ECOG PS $($ median $=1) \ddagger$} \\
\hline $0-1$ & 26 of $39(67)$ & 31 \\
\hline $2-3$ & 10 of $39(26)$ & 46 \\
\hline 4 & 3 of $39(8)$ & 12 \\
\hline NS & $0(0)$ & 10 \\
\hline $\mathrm{LDH}>\operatorname{normal}(240 \mathrm{U} / \mathrm{L}) \ddagger$ & 1 of $20(5)$ & 35 \\
\hline ocular disease末 & 0 of $31(0)$ & 13 \\
\hline pos CSF cytology $\ddagger$ & 4 of $25(16)$ & 16 \\
\hline CSF protein level $>$ normal $(45 \mathrm{mg} / \mathrm{dl}) \ddagger$ & 15 of $18(83)$ & 61 \\
\hline multiple lesions & 7 of $39(18)$ & 34 \\
\hline involvement of deep structures§ & $10(25)$ & 36 \\
\hline \multicolumn{3}{|l|}{ site of diseasell } \\
\hline cerebral hemisphere & $32(80)$ & 67 \\
\hline basal ganglia & $5(13)$ & $\begin{array}{l}28 \text { (basal ganglia } \\
\& \text { corpus callosum) }\end{array}$ \\
\hline corpus callosum & $5(13)$ & \\
\hline brainstem & $0(0)$ & 6 \\
\hline cerebellum & $1(3)$ & 6 \\
\hline meninges** & $2(5)$ & 1 \\
\hline spinal cord & $1(3)$ & 1 \\
\hline \multicolumn{3}{|l|}{ outcome } \\
\hline 2-yr overall survival & $65 \%$ (CI 50-80\%) & 37 \\
\hline 2-yr progression-free survival & $60 \%$ (CI 44-76\%) & 32 \\
\hline median progression-free survival & $61.5 \mathrm{mos}$, range $0-204 \mathrm{mos}$ & $9 \mathrm{mos}$ \\
\hline
\end{tabular}

* Adapted from Jahnke, et al. (2006). Abbreviations: ECOG PS = Eastern Cooperative Oncology Group performance status; LDH = lactate dehydrogenase; $\mathrm{NS}=$ not specified; pos = positive; $-=$ not reported

$\dagger$ The median age was 60 years (range 19-78 years).

$\$$ Percentage based on the number of positive cases divided by the number of cases with available information.

$\S$ Deep structures of the brain include basal ganglia, brainstem, corpus callosum, and/or cerebellum.

II Some patients had involvement of multiple sites.

** $\quad$ Exclusive site of disease.

Combined chemotherapy and radiotherapy was used in 15 patients, radiotherapy alone was used in 12, chemotherapy alone in 10, tumor resection alone in two, and one patient received no treatment. The long-term results for low-grade PCNSL were more favorable when compared with the reports in the literature for high-grade PCNSL, from which we may infer a better prognosis. ${ }^{5,9,10}$ The 2year overall survival rate was $65 \%$ (CI 50-80\%), 2-year progression-free survival was $60 \%$ (CI 44-76\%), and the median progression-free survival was 61.5 months (range 0-204 months). Two patients were alive without evidence of the disease 40 and 20.5 months after tumor resection alone, and three whose tumors did not respond to treatment were alive and progression free without further therapy after $85.5,63$, and 39.5 months.

The indolent course of low-grade PCNSL, long-term survival compared with patients who have high-grade PCNSL, and the possibility of disease control with focal treatment or even no treatment, all denote similarities to the clinical course of systemic low-grade lymphomas. Extrapolating paradigms in the treatment of systemic lowgrade lymphomas, focal radiotherapy could conceivably be considered the primary treatment, avoiding the late neurotoxicity seen in whole-brain irradiation, and chemotherapy (high-dose methotrexate) could be deferred until progression or relapse.

\section{The T-cell Lymphomas}

The T-cell CNS lymphomas, although very rare, are oc-

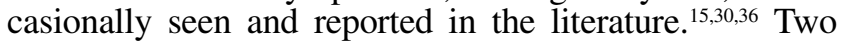
large series of PCNSL from France and Japan show an incidence of T-cell PCNSL of 3.6 and $8.5 \%$, respective$1 y .{ }^{2,17}$ In the largest series of PCNSL reported to date in Western countries, Ferreri, et al., ${ }^{12}$ found eight cases $(2 \%)$ of T-cell PCNSL among 370 patients in whom PCNSL was diagnosed. Choi, et al. ${ }^{8}$ reported 42 cases of PCNSL in Korea and found a $16.7 \%$ incidence of T-cell PCNSL. 


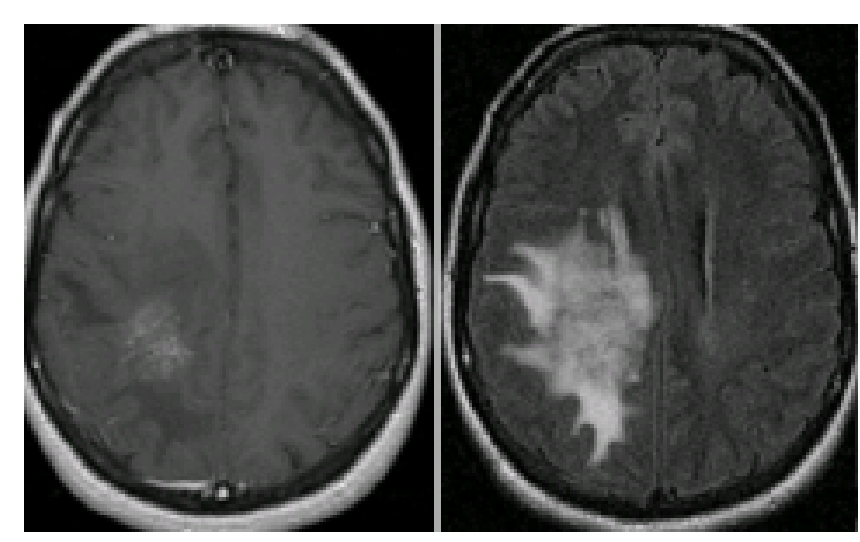

FIG. 1. Axial MR images of a low-grade PCNSL, demonstrating inhomogeneous contrast enhancement (left) and hyperintense fluid-attenuated inversion-recovery signal (right).

Their cases did not show male predominance as reported by Novak and Katzin, ${ }^{34}$ and neither did they show the preponderance of infratentorial location identified by Ferreri, et al.; ${ }^{12}$ however, all tumors originated in the superficial subcortical area, raising the possibility that the pathogenesis of the T-cell PCNSL differs from diffuse large B-cell lymphoma. Kim and Kim, ${ }^{26}$ analyzing MR imaging findings in patients with T-cell PCNSL, found a predilection for a subcortical location, a relatively high incidence of cortical or intratumoral hemorrhage, rim enhancement, and cystic areas consistent with necrosis.

Recently Shenkier, et al. ${ }^{42}$ of the IPCG reported a retrospective series of 45 patients with T-cell PCNSL compiled from individuals treated in 12 cancer centers in seven countries (Table 2). Clinical data obtained from this study appear to be similar to the series of PCNSL published by Ferreri, et al., ${ }^{13}$ from the IELSG, with respect to median age, performance status, and lesion location. The T-cell PCNSL group has a greater male preponderance, a higher proportion of patients with B (systemic) symptoms, and a lower incidence of ocular involvement. Even with these findings, further studies are needed until we can draw definitive conclusions about the clinical differences between T- and B-cell PCNSL.

Heterogeneity in the results of histopathological studies was found among T-cell PCNSLs in 25 patients whose tumor pathology was reviewed. In seven cases $(28 \%)$ the tumor was described as "angiocentric." In 12 cases (48\%) the cell size was described as "small" or "small to medium," and in 13 cases the cells were described as either "pleomorphic" or composed of "medium to large cells." Amid the latter 13 cases, three had features of anaplastic large cell lymphoma and positive staining for CD30 in addition to $\mathrm{CD} 3$. In one report eight cases of anaplastic large cell lymphoma were described, but the outcome in these patients was similar to that in other cases of PCNSL. ${ }^{38}$ The small cell variant of T-cell PCNSL also described in the IPCG series did not seem to affect the overall patient survival, although some reports do link this variant to a more indolent course and therefore to a better prognosis. ${ }^{49}$ Tumor sections from a case of T-cell PCNSL are depicted in Fig. 2.

In the IPCG series, management of this tumor consisted of systemic chemotherapy followed by irradiation in 24
TABLE 2

Characteristics of 45 patients with T-cell PCNSL enrolled in the IPCLCG compared with 378 with PCNSL in the IELSG*

\begin{tabular}{|c|c|c|}
\hline Characteristic & $\begin{array}{l}\text { No. of Patients }(\%) \\
\text { in IPCLCG }\end{array}$ & $\begin{array}{l}\% \text { of Patients } \\
\text { in IELSG }\end{array}$ \\
\hline \multicolumn{3}{|l|}{ age in yrs } \\
\hline median & 59.5 & 61 \\
\hline range & $3-84$ & $14-85$ \\
\hline $70 \mathrm{yrs}$ & $6(13)$ & 14 \\
\hline no. of males & $35(78)$ & 58 \\
\hline B symptoms & $5(11)$ & 2 \\
\hline \multicolumn{3}{|l|}{ ECOG PS } \\
\hline $0-1$ & 20 of $41(48)$ & 31 \\
\hline $2-3$ & 20 of 41 (48) & 46 \\
\hline 4 & 1 of $41(2)$ & 12 \\
\hline $\mathrm{LDH}>\operatorname{normal}(240 \mathrm{U} / \mathrm{L}) \dagger$ & 7 of $22(32)$ & 35 \\
\hline ocular disease $\dagger$ & 1 of $26(4)$ & 13 \\
\hline $\begin{array}{l}\text { CSF protein level }>\text { normal } \\
\qquad(45 \mathrm{mg} / \mathrm{dl}) \dagger\end{array}$ & 19 of 24 (79) & 61 \\
\hline pos CSF cytology $\dagger$ & 6 of $32(19)$ & 16 \\
\hline multiple lesions & $13(29)$ & 34 \\
\hline $\begin{array}{l}\text { involvement of deep structures } \\
\text { site of disease } \$\end{array}$ & $16(36)$ & 36 \\
\hline cerebral hemisphere & $29(64)$ & 67 \\
\hline basal ganglia & $5(11)$ & $\begin{array}{c}28 \text { (basal } \\
\text { ganglia } \\
\& \text { corpus } \\
\text { callosum) }\end{array}$ \\
\hline corpus callosum & $6(13)$ & \\
\hline brainstem & $4(9)$ & 6 \\
\hline cerebellum & $3(7)$ & 6 \\
\hline meninges\|l & $1(2)$ & 1 \\
\hline spinal cord & $2(4)$ & 1 \\
\hline
\end{tabular}

* Adapted from Ferreri, et al. (2002). Abbreviation: IPCLCG = International Primary CNS Lymphoma Collaborative Group.

$\dagger$ Percentage based on number of positive cases divided by number of cases with available information.

\$Deep structures of the brain include basal ganglia, brainstem, corpus callosum, and cerebellum.

$\S$ Some patients had involvement of multiple sites.

I| Exclusive site of disease.

patients, systemic chemotherapy alone in nine, and irradiation alone in 11 . The remaining patient died before treatment was given, and the diagnosis was made at autopsy. Among the 33 patients who received chemotherapy, highdose methotrexate was administered alone (11) or with other agents (18) in 29 patients. The median dose of methotrexate was $4 \mathrm{~g} / \mathrm{m}^{2} /$ month and the mean number of individual treatments administered was five. Thirty-four of the 35 patients who underwent radiotherapy were treated with whole-brain irradiation and the median dose was 35 Gy. The other patient, who had a spinal cord lesion, underwent spinal irradiation only. The median diseasespecific survival was 25 months, a period that resembles the outcome reported in the IELSG of a 37\% 2-year overall survival rate. ${ }^{12}$

We conclude that T-cell PCNSL can be treated with a similar therapeutic approach to the one used in general for PCNSL, and the only two variants that seem to be associated with a better outcome are good performance status and the use of methotrexate.

Recently Kaluza, et al.,${ }^{24}$ published the first case in the literature of a primary brain lymphoma natural killer/Tcell lesion with a characteristic phenotype expressing CD3 
A. Neves Da Silva, M. B. Lopes, and D. Schiff

epsilon, CD56, granzyme B, Epstein-Barr virus-encoded small nuclear RNAs, with a germline T-cell receptor gene configuration, and displaying an unusual intravascular component. The patient underwent extensive evaluation and disease was found in the CNS only (that is, the brain). His tumor responded poorly to high-dose methotrexate, and he eventually died of progressive disease and clinical complications.

\section{Burkitt PCNSL}

Burkitt lymphoma is a childhood tumor that commonly affects abdominal organs. Involvement of the CNS is usually secondary and a manifestation of advanced systemic disease. Few cases of immunocompetent patients with the Burkitt type of PCNSL are reported in the literature. ${ }^{33,40,43,45}$ Spath-Schwalbe, et al., reported a case of a highly malignant B-cell lymphoma of the Burkitt type that responded partially to methotrexate: full remission was achieved with radiation therapy that had lasted for more than 1 year at the time of publication. Toren, et al., ${ }^{45}$ described the case of a 6-year-old immunocompetent girl whose clinical diagnosis was Guillain-Barré syndrome but whose immunological, cytological, and molecular CSF studies were diagnostic for primary CNS Burkitt lymphoma. After aggressive systemic and intrathecal chemotherapy, remission was achieved and the patient's disease was in complete remission 2 years later when the paper was published.

Hochberg, et al. ${ }^{19}$ reported on an immunocompetent patient with PCNSL and serological evidence of recent primary infection with the Epstein-Barr virus, suggesting that the lymphoma would have been induced by the virus. Monabati, et al., ${ }^{33}$ reported another case of an immunocompetent patient, in whom testing for the Epstein-Barr virus produced negative results, who had a PCNSL in which histopathological studies revealed a high-grade non-Hodgkin lymphoma of the small, noncleaved, Burkitt type.

In summary, cases of primary CNS Burkitt lymphoma with or without concomitant infection with the Epstein-Barr virus, although very rare, have been reported and may represent another unusual variant of PCNSL.

\section{Neurolymphomatosis}

The term "neurolymphomatosis" has been used to describe infiltration of the peripheral nervous system by lymphoma and nontumorous lymphocytes. It may include these aspects: involvement of the cranial and peripheral nerve roots or plexus and CT and/or MR imaging or intraoperative evidence of nerve enlargement, and/or enhancement beyond the dural sleeve in patients with previous or concurrent PCNSL or systemic lymphoma. ${ }^{1}$ This entity was initially described by Lhermitte and Trelles ${ }^{32}$ in 1934 , even before the identification of B lymphocytes as the most common causative agents of PCNSL. Few cases of this rare presentation of PCNSL have been reported in the literature. $1,6,28,46,48$

In 2003, Baehring, et al., ${ }^{1}$ published the most comprehensive paper about neurolymphomatosis up to that time, compiling 25 cases from Massachusetts General Hospital in addition to 47 cases already reported in the literature.


FIG. 2. Photomicrographs showing a T-cell lymphoma arising in the left parietal region of a 48-year-old man. Extensive inflammatory infiltration was present diffusely in the parenchyma with prominence in the perivascular areas (A and B). Immunohistochemical stains were positive for several T-cell markers, including CD3 (C and D) and CD5 (E), whereas B-cell markers, including $\mathrm{CD} 20(\mathrm{~F})$, were negative. $\mathrm{H} \& \mathrm{E}(\mathrm{A}$ and $\mathrm{B})$ and immunohistochemical staining for CD3 (C and D), CD5 (E), and CD20 (F). Original magnification $\times 200(\mathrm{~A}-\mathrm{D}$ and $\mathrm{F})$ and $\times 100(\mathrm{E})$

Among the 72 patients, the median age was the late 50 s to early 60s (range 17-84 years of age), and there was no sex predominance. The patients fit into four basic patterns, as follows: 1) painful involvement of nerve or roots; 2) cranial neuropathy with or without pain; 3) painless involvement of peripheral nerves; and 4) painful or painless involvement of a single peripheral nerve. Usually the final diagnosis of neurolymphomatosis took months to years as a consequence of an alternative diagnosis. Neural involvement with lymphoma is difficult to detect even with the aid of MR imaging, and in the series reported by Baehring, et al., enhancement of nerves or roots was seen in only $29(40 \%)$ of the 72 cases. The diffuse thickening and enhancement of peripheral or cranial nerves are best demonstrated with coronal sequences on MR imaging studies ${ }^{41}$ although those attributes are not pathognomonic features of neurolymphomatosis and can be found in inflammatory processes. Trojan, et al., ${ }^{47}$ proposed a fusion of positron emission tomography and CT as a valuable tool to aid in the diagnosis of peripheral nerve involvement in lymphomas.

In 64 of the patients in the series published by Baehring, et al., the definitive diagnosis of neurolymphomatosis was accomplished by assessing biopsy samples of tissue from an infiltrated nerve in 24 patients and by autopsy in 41 . In one patient in whom results of the nerve biopsy were pos- 
itive, a postmortem examination was also performed. In the other eight patients, the diagnosis of neurolymphomatosis was made based on clinical presentation, nodular nerve enlargement or enhancement, and lymphoma cells in spinal fluid or extraneural sites. In contrast with the usual forms of PCNSL, in which the diagnosis can be made after a brain lesion biopsy procedure or CSF cytology study in up to $90 \%$ of cases,$^{41}$ in the Baehring series only $55 \%$ of the patients were diagnosed while still alive. In the vast majority of patients the diagnosis was large Bcell lymphoma with a high proliferation index when stained with MIB-1, and four cases compiled from the literature were T-cell lymphomas. Prior systemic non-Hodgkin lymphoma existed in 14 patients (19\%), a coincident diagnosis of this disease and neurolymphomatosis was found in 11 cases (15\%), and in four patients clinically recognized systemic dissemination of lymphoma developed after the diagnosis of neurolymphomatosis. Dissemination to systemic sites and brain parenchyma occurred in 53 individuals (73\%) as determined by biopsy sampling or autopsy procedures, and 19 patients with neurolymphomatosis $(26 \%)$ suffered from parenchymal CNS lymphoma, although this complication was identified before autopsy in only 10 patients.

Treatment of neurolymphomatosis follows the principles of treatment for the usual forms of PCNSL. Systemic steroid drugs show a transient benefit, and chemotherapy should include high-dose methotrexate, which is used in other forms of PCNSL. ${ }^{3}$ Because most of the large B-cell PCNSLs express the cell surface molecule CD20, there may be a role for rituximab, an anti-CD20 monoclonal antibody. ${ }^{37,39}$ Locoregional irradiation may also be used in the classic neurolymphomatosis setting of peripheral nerve thickening or enhancement. ${ }^{41}$

The outcome of neurolymphomatosis was not reported in the Baehring series, but some patients appear to have a protracted course with peripheral or cranial mono- or polyneuropathy. This circumstance requires a high degree of suspicion on the part of the clinician to order tests like MR imaging or fusion positron emission tomography-CT to identify the nerve thickening and/or enhancement that can lead to a biopsy procedure for definitive histopathological diagnosis. The standard PCNSL staging tests should be included in the routine evaluation when neurolymphomatosis is suspected. ${ }^{41}$

\section{Pituitary PCNSL}

Few cases of PCNSL presenting as pituitary tumor have been reported in the literature. ${ }^{16,20,25,31,44}$ Besides acquired immunodeficiency syndrome and other immunodeficiency conditions, lymphocytic hypophysitis and pituitary adenomas have been implicated as risk factors for pituitary lymphomas. Recently Huang, et al. ${ }^{20}$ reported a case of a 47-year-old man with primary pituitary lymphoma presenting as hypophysitis. The pathological investigation revealed infiltration of atypical T-lymphoid cells and the concomitant presence of B-lymphoid cells. In this patient systemic metastasis eventually developed 6 months after initial presentation, and a biopsy sample of the liver lesion revealed exclusively $\mathrm{T}$ cells, confirming the aggressive nature of this tumor. A case of mucosa-associated lym- phoid tissue lymphoma of the pituitary gland presenting as a homogeneously enhancing solid mass in the sellar region and in both parasellar regions was also reported. ${ }^{31}$

Landman, et al. ${ }^{29}$ reported a case of an 86-year-old man who presented with fever of unknown origin and hypopituitarism. Results on MR imaging were consistent with pituitary adenoma, and a transsphenoidal resection showed a B-cell lymphoma. On imaging the differential diagnosis between primary pituitary lymphoma and a pituitary adenoma is not easy, but one should consider lymphoma when evaluating an invasive sellar mass that is iso- to hypointense on $\mathrm{T}_{2}$-weighted MR images. ${ }^{25}$

The outcome of the patients with pituitary lymphomas reported in the literature seems to be better than in those with the most common forms of PCNSL, ${ }^{16}$ but because of the small number of cases effectively reported and followed, the outcome, clinical features, and treatment remain largely unknown.

\section{References}

1. Baehring JM, Damek D, Martin EC, Betensky RA, Hochberg FH: Neurolymphomatosis. Neuro-oncol 5:104-115, 2003

2. Bataille B, Delwail V, Menet E, Vandermarcq P, Ingrand P, Wager $\mathrm{M}$, et al: Primary intracerebral malignant lymphoma: report of 248 cases. J Neurosurg 92:261-266, 2000

3. Batchelor T, Carson K, O'Neill A, Grossman SA, Alavi J, New $\mathrm{P}$, et al: Treatment of primary CNS lymphoma with methotrexate and deferred radiotherapy: a report of NABTT 96-07. J Clin Oncol 21:1044-1049, 2003

4. Batchelor T, Loeffler JS: Primary CNS lymphoma. J Clin Oncol 24:1281-1288, 2006

5. Blay JY, Conroy T, Chevreau C, Thyss A, Quesnel N, Eghbali $\mathrm{H}$, et al: High-dose methotrexate for the treatment of primary cerebral lymphomas: analysis of survival and late neurologic toxicity in a retrospective series. J Clin Oncol 16:864-871, 1998

6. Borit A, Altrocchi PH: Recurrent polyneuropathy and neurolymphomatosis. Arch Neurol 24:40-49, 1971

7. CBTRUS: Statistical Report: Primary Brain Tumors in the United States 1995-1999. Chicago: Central Brain Tumor Registry of the United States, 2002

8. Choi JS, Nam DH, Ko YH, Seo JW, Choi YL, Suh YL, et al: Primary central nervous system lymphoma in Korea: comparison of B- and T-cell lymphomas. Am J Surg Pathol 27: 919-928, 2003

9. DeAngelis LM: Primary central nervous system lymphomas. Curr Treat Options Oncol 2:309-318, 2001

10. DeAngelis LM, Seiferheld W, Schold SC, Fisher B, Schultz CJ: Combination chemotherapy and radiotherapy for primary central nervous system lymphoma: Radiation Therapy Oncology Group study 93-10. J Clin Oncol 20:4643-4648, 2002

11. Eby NL, Grufferman S, Flannelly CM, Schold SC, Jr, Vogel FS, Burger PC: Increasing incidence of primary brain lymphoma in the US. Cancer 62:2461-2465, 1988

12. Ferreri AJ, Blay JY, Reni M, Pasini F, Spina M, Ambrosetti A, et al: Prognostic scoring system for primary CNS lymphomas: the International Extranodal Lymphoma Study Group experience. J Clin Oncol 21:266-272, 2003

13. Ferreri AJM, Reni M, Pasini F, Calderoni A, Tirelli U, Pivnik A, et al: A multicenter study of treatment of primary CNS lymphoma. Neurology 58:1513-1520, 2002

14. Fine HA, Loeffler JS: Primary central nervous system lymphoma, in Canellos G, Lister TA, Sklar JL (eds): The Lymphomas. Philadelphia: WB Saunders, 1998, pp 481-494

15. Gijtenbeek JMM, Rosenblum MK, DeAngelis LM: Primary central nervous system T-cell lymphoma. Neurology 57: 716-718, 2001 
A. Neves Da Silva, M. B. Lopes, and D. Schiff

16. Giustina A, Gola M, Doga M, Rosei EA: Primary lymphoma of the pituitary: an emerging clinical entity. J Clin Endocrinol Metab 86:4567-4575, 2001

17. Hayabuchi N, Shibamoto Y, Onizuka Y: Primary central nervous system lymphoma in Japan: a nationwide survey. Int J Radiat Oncol Biol Phys 44:265-272, 1999

18. Hochberg FH, Miller DC: Primary central nervous system lymphoma. J Neurosurg 68:835-853, 1988

19. Hochberg FH, Miller G, Schooley RT, Hirsch MS, Feorino P, Henle W: Central-nervous-system lymphoma related to Epstein-Barr virus. N Engl J Med 309:745-748, 1983

20. Huang YY, Lin SF, Dunn P, Wai YY, Hsueh C, Tsai JS: Primary pituitary lymphoma presenting as hypophysitis. Endocr J 52:543-549, 2005

21. Jahnke K, Korfel A, O'Neill BP, Blay JY, Abrey LE, Martus P, et al: International study on low-grade primary central nervous system lymphoma. Ann Neurol 59:755-762, 2006

22. Jahnke K, Thiel E, Schilling A, Herrlinger U, Weller M, Coupland SE, et al: Low-grade primary central nervous system lymphoma in immunocompetent patients. Br J Haematol 128: 616-624, 2005

23. Kadan-Lottick NS, Skluzacek MC, Gurney JG: Decreasing incidence rates of primary central nervous system lymphoma. Cancer 95:193-202, 2002

24. Kaluza V, Rao DS, Said JW, de Vos S: Primary extranodal nasal-type natural killer/T-cell lymphoma of the brain: a case report. Hum Pathol 37:769-772, 2006

25. Kaufmann TJ, Lopes MB, Laws ER Jr, Lipper MH: Primary sellar lymphoma: radiologic and pathologic findings in two patients. AJNR Am J Neuroradiol 23:364-367, 2002

26. Kim EY, Kim SS: Magnetic resonance findings of primary central nervous system T-cell lymphoma in immunocompetent patients. Acta Radiol 46:187-192, 2005

27. Krogh-Jensen M, Johansen P, D’Amore F: Primary central nervous system lymphomas in immunocompetent individuals: histology, Epstein-Barr virus genome, Ki-67 proliferation index, p53 and bcl-2 gene expression. Leuk Lymphoma 30:131-142, 1998

28. Kuroda Y, Nakata H, Kakigi R, Oda K, Shibasaki H, Nakashiro $\mathrm{H}$ : Human neurolymphomatosis by adult T-cell leukemia. Neurology 39:144-146, 1989

29. Landman RE, Wardlaw SL, McConnell RJ, Khandji AG, Bruce JN, Freda PU: Pituitary lymphoma presenting as fever of unknown origin. J Clin Endocrinol Metab 86:1470-1476, 2001

30. Lee DK, Chung CK, Kim HJ, Kim K, Choe G, Moon CW, et al: Multifocal primary CNS T cell lymphoma of the spinal cord. Clin Neuropathol 21:149-155, 2002

31. Lee JH, Lee HK, Choi CT, Huh J: Mucosa-associated lymphoid tissue lymphoma of the pituitary gland: MR imaging features. AJNR Am J Neuroradiol 23:838-840, 2002

32. Lhermitte J, Trelles JO: Neurolymphomatose peripherique humaine. Presse Med 42:289-292, 1934

33. Monabati A, Rakei SM, Kumar PV, Taghipoor M, Rahimi A: Primary burkitt lymphoma of the brain in an immunocompetent patient. Case report. J Neurosurg 96:1127-1129, 2002

34. Novak JA, Katzin WE: Primary central-nervous-system T-cell lymphoma with a predominant CD8 immunophenotype. Cancer 75:2180-2185, 1995

35. Olson JE, Janney CA, Rao RD, Cerhan JR, Kurtin PJ, Schiff D, et al: The continuing increase in the incidence of primary central nervous system non-Hodgkin lymphoma: a surveillance, epidemiology, and end results analysis. Cancer 95: 1504-1510, 2002

36. Paulus W, Jellinger KA: A case of primary central nervous system lymphoma (PCNSL) of putative T-cell lineage. J Neurooncol 18:83-84, 1994 (Letter)

37. Pels H, Schulz H, Schlegel U, Engert A: Treatment of CNS lymphoma with the anti-CD20 antibody rituximab: experience with two cases and review of the literature. Onkologie 26: 351-354, 2003

38. Ponzoni M, Terreni MR, Ciceri F, Ferreri AJM, Gerevini S, Anzalone N, et al: Primary brain CD30+ ALK1+ anaplastic large cell lymphoma ('ALKoma'): The first case with a combination of 'not common' variants. Ann Oncol 13:1827-1832, 2002

39. Rubenstein JL, Combs D, Rosenberg J, Levy A, McDermott M, Damon L, et al: Rituximab therapy for CNS lymphomas: targeting the leptomeningeal compartment. Blood 101: 466-468, 2003

40. Shehu BB: Primary central nervous system Burkitt's lymphoma presenting with proptosis. Ann Trop Paediatr 23:319-320, 2003

41. Shenkier TN: Unusual variants of primary central nervous system lymphoma. Hematol Oncol Clin North Am 19:651-664, 2005

42. Shenkier TN, Blay JY, O'Neill BP, Poortmans P, Thiel E, Jahnke K, et al: Primary CNS lymphoma of T-cell origin: a descriptive analysis from the international primary CNS lymphoma collaborative group. J Clin Oncol 23:2233-2239, 2005

43. Spath-Schwalbe E, Genvresse I, Stein H, Gelderblom H, Lehmann R, Budach V, et al: Primary cerebral highly-malignant Bcell lymphoma of the Burkitt type. Dtsch Med Wochenschr 124:451-455, 1999

44. Stephens JW, Morganstein DL, McLaughlin JE, Dorwood N, Vanderpump MP: Isolated B-cell lymphoma of the pituitary region: a rare clinical entity. Hosp Med 63:306-307, 2002

45. Toren A, Mandel M, Shahar E, Rimmoni E, Roizin H, Neuman Y, et al: Primary central nervous system Burkitt's lymphoma presenting as Guillain-Barre syndrome. Med Pediatr Oncol 23:372-375, 1994

46. Trelles JO, Trelles L: Human peripheral neurolymphomatosis. Rev Neurol (Paris) 139:703-714, 1983

47. Trojan A, Jermann M, Taverna C, Hany TF: Fusion PET-CT imaging of neurolymphomatosis. Ann Oncol 13:802-805, 2002

48. Vallat JM, De Mascarel HA, Bordessoule D, Jauberteau MO, Tabaraud F, Gelot A, et al: Non-Hodgkin malignant lymphomas and peripheral neuropathies-13 cases. Brain 118: 1233-1245, 1995

49. Villegas E, Villa S, López-Guillermo A, Petit J, Ribalta T, Graus F: Primary central nervous system lymphoma of T-cell origin: description of two cases and review of the literature. J Neurooncol 34:157-161, 1997

Manuscript received August 15, 2006.

Accepted in final form October 4, 2006

Address reprint requests to: David Schiff, M.D, Neurology Department, Division of Neuro-Oncology, University of Virginia Health Sciences Center, Jefferson Park Avenue, Hospital West, Room 6228, PO Box 800432, Charlottesville, Virginia 22908-0432. email: davidschiff@ virginia.edu. 